\title{
Vein is a novel component in the Drosophila epidermal growth factor receptor pathway with similarity to the neuregulins
}

\author{
Bruce Schnepp, Gary Grumbling, Timothy Donaldson, and Amanda Simcox ${ }^{1}$ \\ Department of Molecular Genetics, The Ohio State University, Columbus, Ohio 43210 USA
}

The activation signal from tyrosine kinase receptors, such as the epidermal growth factor receptor (EGFR), is relayed via a highly conserved intracellular pathway involving Ras, Raf, and MAPK. In Drosophila, the EGFR and components of the intracellular pathway are broadly expressed, yet receptor activation evokes tissue-specific cell responses. Extracellular events that lead to receptor activation are one mechanism by which signaling is modulated. Here we show molecular and genetic evidence that Drosophila vein (vn) encodes a candidate EGFR ligand and that $v$ expression is spatially restricted. Consequently, vn may promote tissue-specific receptor activation. Unlike two other ligands, Gurken (Grk) and Spitz (Spi), which are transforming growth factor $\alpha$-like proteins, Vn has both an immunoglobulin-like and an EGF-like domain. This combination of domains mirrors those in the vertebrate neuregulins that bind EGFR relatives.

[Key Words: vein; Drosophila; EGF receptor; EGF; neuregulin]

Received April 24, 1996; revised version accepted August 7, 1996.

The Drosophila epidermal growth factor receptor (DER) is a receptor tyrosine kinase of the epidermal growth factor receptor (EGFR) subfamily that currently also includes four vertebrate proteins (EGFR/erbB1, neu/erbB2, erbB3, and erbB4) and Caenorhabditis elegans Let-23. These receptors have important roles in development: EGFR mutant mice have epithelial defects that cause a number of phenotypes and early death (Miettinen et al. 1995; Sibilia and Wagner 1995; Threadgill et al. 1995); $n e u$ and $e r b B 4$ mutant embryos die in utero with heart and neural defects /Gassmann et al. 1995; Lee et al. 1995); let-23 is involved in determining vulval cell fate (Aroian et al. 1990; Hill and Sternberg 1992); and DER has multiple roles in Drosophila development involving cell survival, proliferation, and differentiation in embryos, imaginal discs, and the ovary (Shilo and Raz 1991; Clifford and Schüpbach 1992; Raz and Shilo 1992; Baumann and Skaer 1993; Raz and Shilo 1993; Xu and Rubin 1993; Clifford and Schüpbach 1994; Kuo et al. 1996). EGFR-class receptors are activated by ligands that have an EGF-like domain, and one known route of intracellular signal transduction from the activated receptors is through the highly conserved Ras/Raf/MAPK pathway, which is also common to a number of other receptor tyrosine kinases (Egan and Weinberg 1993).

The tissue specificity of signaling from EGFRs is

${ }^{1}$ Corresponding author. achieved in part by spatially restricted extracellular factors such as ligands. For example, in the developing mouse heart, the ligand, neuregulin, limits the functional domain of neu and erbB4 to a subset of the cells that express these receptors (Gassmann et al. 1995; Lee et al. 1995; Meyer and Birchmeier 1995). In C. elegans and Drosophila there are two striking examples of ligand localization restricting receptor function. In C. elegans vulval development, lin-3, which encodes the Let-23 ligand, is expressed by the single anchor cell and produces a local source of ligand for activation of the receptor only in the overlying presumptive vulval cells (Hill and Sternberg 1992). Drosophila Grk is an oogenesis-specific EGF-like ligand involved in establishing egg polarity (Neuman-Silberberg and Schüpbach 1993; GonzálezReyes et al. 1995; Roth et al. 1995). grk transcripts are localized to the anterior-dorsal region of the oocyte and a local source of Grk is thought to activate DER only in the adjacent follicle cells (Neuman-Silberberg and Schüpbach 1993).

A structure and function analysis of DER suggests it is regulated by multiple ligands /Clifford and Schüpbach 1994), and two candidates in addition to Grk have been identified. These are the EGF-like proteins Spi, which activates DER function, and Argos, which inhibits DER function (Freeman et al. 1992; Rutledge et al. 1992; Neuman-Silberberg and Schüpbach 1993; Schweitzer et al. 1995a,b; Golembo et al. 1996). Spi and Argos are zygotically active in both the embryo and the adult. spi mu- 
tants are embryonic lethal and have a complex phenotype, involving cells derived from the ventral ectoderm, which includes a deletion of ventral cuticle (Mayer and Nüsslein-Volhard 1988; Rutledge et al. 1992). DER, rhomboid (rho), Star (S), and pointed (pnt) have mutant phenotypes similar to spi and are collectively called the spitz group (Mayer and Nüsslein-Volhard 1988; Bier et al. 1990; Clifford and Schüpbach 1992; Raz and Shilo 1992; Rutledge et al. 1992; Kim and Crews 1993; Klämbt 1993). argos mutants have the opposite phenotype, whereby there is an expansion of the ventral cuticle that is lost in spi-group mutants (Freeman et al. 1992; Golembo et al. 1996). Molecular characterization and genetic interactions of the spi-group suggest these genes are involved in potentiating DER signaling (Díaz-Benjumea and García-Bellido 1990; Rutledge et al. 1992; Klämbt 1993; Raz and Shilo 1993; Sturtevant et al. 1993). The biochemical roles of some of the genes are known. Pnt is a target of Rolled/MAPK (Rl) and thus may act at the end of the pathway (Biggs et al. 1994; Brunner et al. 1994a; O'Neill et al. 1994). The biochemical roles of Rho and $\mathrm{S}$ are not known, but both are membrane proteins, and may be involved in the processing of Spi into its active form, secreted Spi (Bier et al. 1990; Kolodkin et al. 1994; Schweitzer et al. 1995b). There is direct evidence Spi activates DER and that this activation can be competed by Argos (Schweitzer et al. 1995a). Thus, these two proteins act as ligands to modulate DER activation. DER is broadly expressed in embryos, including cells that are not affected in mutants, likewise, its ligand, $\mathrm{Spi}$, is also broadly expressed (Schejter et al. 1986; Kammermeyer and Wadsworth 1987; Zak et al. 1990; Katzen et al. 1991; Rutledge et al. 1992; Sturtevant et al. 1994). Tissue-specific Spi/DER activation may be mediated by spatially localized cofactors encoded by other spi-group genes such as $S$ and $r$ ho (Schweitzer et al. 1995b).

Here we show molecular and genetic data that strongly link vn to the DER pathway and suggest it encodes a novel ligand for DER. $v n$ was discovered as a mutant with abnormal wing venation but additional alleles, originally called defective dorsal discs (ddd) suggest the gene has a more extensive role in wing development affecting the global proliferation of wing disc cells (Shearn et al. 1971; Puro 1982; Wurst et al. 1984; Simcox et al. 1987). We show $v n$ also functions in larval patterning and, furthermore, acts synergistically with spi. vn expression is spatially and temporally restricted and, thus, it may encode another extracellular factor which regulates tissue-specific activation of DER.

\section{Results}

\section{Molecular cloning of the vn locus}

The P-element in the $v n^{D 4}$ allele was used as a cloning tag to isolate $52 \mathrm{~kb}$ of DNA in the vn region (Fig. 1A). Ten lesions associated with vn mutants map to this 52 $\mathrm{kb}$ region (Fig. 1A). Two of these lesions, $v n^{d d d R Y}$ and $v n^{\gamma 4}$ are phenotypic and molecular nulls that disrupt the transcribed region (Fig. 1A). Northern analysis shows that there are two transcripts from the gene of 5 and 6.8 $\mathrm{kb}$, which are expressed throughout development; the larger message is more abundant (data not shown). Ten cDNAs were isolated and their relationship to the genomic DNA and the intron-exon structure of the gene were determined by Southern hybridization and sequencing (Fig. 1A,B). These clones define two cDNAs of 5082 and $6864 \mathrm{bp}$, which correspond in size to the two transcripts seen in Northern analysis (Fig. 1A,B; data not shown). The two cDNAs differ by the presence or absence of a 1782-bp intron (intron 4; Fig. 1A) that is spliced out in the smaller cDNA. Northern analysis with intron 4 as a probe shows hybridization to the $6.8-\mathrm{kb}$ message only (data not shown). These data show the gene makes two messages, a 6.8 -kb message that includes intron 4 and a 5 -kb message in which intron 4 is spliced out. Analysis of the $5^{\prime}$ and $3^{\prime}$ splice site sequences of the 4 introns shows that all have the Drosophila consensus sequence at the $3^{\prime}$ site. At the $5^{\prime}$ site, introns 1-3 match the consensus (GTA/GAGT) exactly (Mount et al. 1992), whereas intron 4 has the sequence GTACAG. This deviation from the consensus may explain why this intron is less efficiently spliced [only 25\% of cDNAs show this splice (see Materials and Methods), and the spliced message is less abundant in Northern blots, data not shown].

We confirmed these transcripts correspond to the vn gene through transformation rescue of $v n$ mutants with a cDNA corresponding to the $5-\mathrm{kb}$ message. A UAS-Vn construct activated by the T80-GAL 4 driver, which is ubiquitously expressed in embryos and discs (data not shown; Wilder and Perrimon, 1995), partially rescued the pattern defects in $v n$ larvae and the proliferation defect in $v n$ wing discs (Fig. 2).

\section{vn encodes secreted EGF-like proteins}

The $v n$ cDNAs encode two predicted proteins that differ only in their extreme carboxy-terminal region (Fig. $1 \mathrm{~B}, \mathrm{C})$. The $5 \mathrm{~kb} \mathrm{cDNA}$ encodes a predicted protein of 622 amino acids (type 1) and the 6.8 - $\mathrm{kb}$ cDNA encodes a predicted protein of 621 amino acids (type 2). These proteins are similar up to residue 606 (the end of exon 4) where they diverge because of the inclusion of a 1782-bp region in the larger cDNA. The type 1 protein ends with 16 amino acids that differ from the terminal 15 amino acids in the type 2 protein (Fig. $1 \mathrm{~B}, \mathrm{C}$ ). Both proteins are predicted to be $\sim 71 \mathrm{kD}$. The function of this carboxyterminal region and the significance, if any, of these protein types is not known.

In the region common to both proteins there are a number of features that suggest function. The predicted proteins begin at a likely translational start site (CGCCATG) (Cavener 1987). This methionine is preceded by stops in all three frames (Fig. 1B). There is a hydrophobic region at the amino terminus that has the characteristics of a signal sequence (Briggs and Gierasch 1986; von Heijne 1986, 1987) and we have shown the protein is indeed secreted (see below). The other features of the proteins are a PEST region that is found in proteins with 
Figure 1. Structure of the vn gene. $(A) \mathrm{Re}$ striction map of the $v n$ region is shown at the top. vn mutations that have been mapped to the region and are shown above (inserts and break points) and below (deletions) the line. The mutations are described in detail elsewhere (Simcox et al. 1996). Boxes represent cDNAs that correspond to the two different messages encoded by vn ( 5 and $6.8 \mathrm{~kb})$. In the larger cDNA (type 2), intron 4 (demarcated by arrows) is not spliced out. Open rectangles represent translated sequences. (B) BamHI; (S) SalI; (T) SstI. (B) Sequence of the 5082-bp vn cDNA (type 1). The open reading frame starts at the first methionine that is preceded by stops in all three frames. There is a signal sequence $(S$; single underline), a PEST region $(\mathrm{P}$; single underline), an opa (polyglutamine) region, an Ig-like domain (boxed), and an EGF-like domain (boxed). Circled residues indicate potential $\mathrm{N}$-linked glycosylation sites and conserved cysteines involved in disulfide bonds are highlighted. Arrows mark intron-exon boundaries. A potential polyadenylation signal is underlined. The 6864bp cDNA (type 2) includes an additional $1782 \mathrm{bp}$ of sequence (not shown), which is spliced out in the 5082-bp cDNA (type 1). Inclusion of the intron gives rise to a predicted protein that is colinear with the type 1 except for the carboxyl terminus (shown below). $(C)$ Carboxy-terminal region of predicted protein encoded by the type 2 cDNA. (Arrow) Exon 4/intron 4 boundary; (arrowhead) start of the region where the two proteins differ at the amino acid level.
A

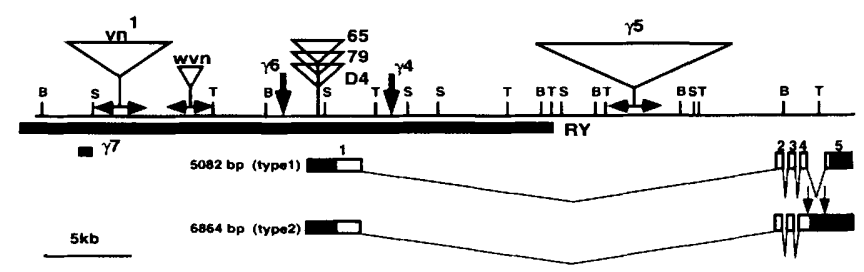

B

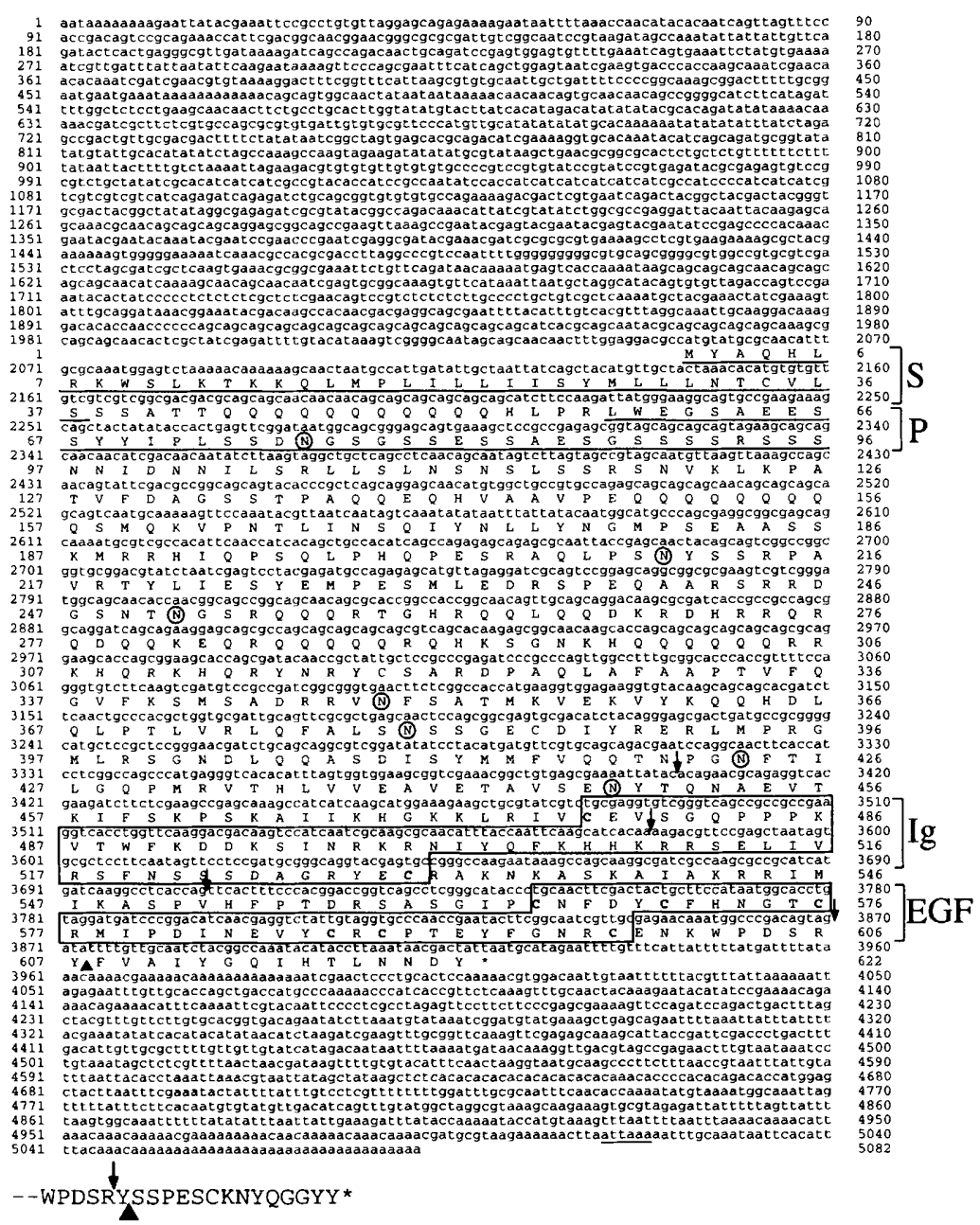

short half-lives (Rogers et al. 1986), an opa (polyglutamine) region (Wharton et al. 1985), an Ig-like domain, and an EGF-like domain. There are a number of residues that are potential $\mathrm{N}$-linked glycosylation sites.

The EGF-like domain in Vn is 43 amino acids long and has the six invariant cysteines and highly conserved gly. cine and arginine residues characteristic of the motif (Fig. 3A; Groenen et al. 1994). The cysteines are thought to form disulfide bonds and, hence, produce a looped structure. The EGF motif in $\mathrm{Vn}$ is between $30 \%$ and $44 \%$ identical to other EGF-like ligands (Fig. 3A). It shares $37 \%$ identity with Spi and $33 \%$ identity with Grk. Amino-terminal to the EGF domain is an Ig-like domain of the $\mathrm{C} 2$ type that include nonimmunological proteins (Fig. 3B; Williams and Barclay 1988). The Ig-like domain in Vn has the two invariant cysteine residues typical of the domain. The Ig region in Vn shares between 33 and
$35 \%$ identity with the Ig region in the neuregulins and is $32 \%$ identical with the Ig region in NCAM (Fig. 3B).

$V n$ is secreted into the medium by S2 Drosophila cells expressing $a$ vn $c D N A$

S2 cells were stably transformed with a vn cDNA under the control of the inducible metallothionein promoter (pMK33 vector). The conditioned media from induced transformed and control cells were analyzed by Western blotting with a rabbit polyclonal anti-Vn antibody. A $\sim 70-\mathrm{kD}$ protein, which reacts with the anti-Vn antibody, is secreted into the medium by Drosophila S2 tissueculture cells expressing a vn cDNA (Fig. 4, lane 2), but not by untransfected control cells (Fig. 4, lane 1). The lower band in lane 2 is presumed to be a breakdown product. 

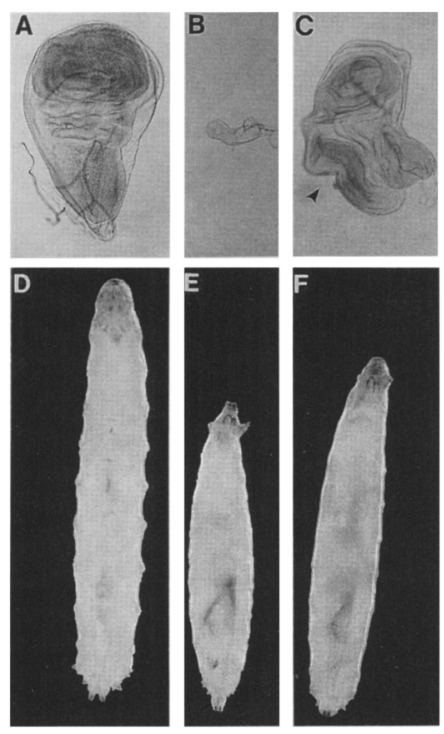

Figure 2. Rescue of $v n$ mutants by a $v n$ cDNA. A $U A S$ - $v n$ gene was expressed in vn mutants with the T80-GAL4 driver, which is expressed ubiquitously in embryos and imaginal discs (data not shown; Wilder and Perrimon 1995). A partial rescue of the wing disc proliferation and larval pattern defects was observed. (A) Wild-type late third instar wing disc. $(B) v n^{d d d L 6 / \gamma 3}$ late third instar wing disc. (C) UAS-vn/T80-GAL4; $v n^{d d d L 6 / \gamma 3}$ late third instar wing disc. The disc is much larger than the vn mutant $\operatorname{disc}(B)$ but the phenotype is not completely wild type $(A)$ as the wing pouch is duplicated (arrowhead). This is a phenotype seen in $v n$ hypomorphs (Simcox et al. 1996). (D) Wild-type late third instar larva. $(E) v n^{d d d L 6 / \gamma^{3}}$ late third instar larva. The larva is smaller and narrower than wild type. The reduction in the width of the larva is most pronounced at the posterior tip. $(F)$ $U A S-v n / T 80-G A L 4 ; v n^{d d d L 6 / \gamma 3}$ late third instar larva. The length and width of the larva are rescued compared with the vn mutant larva $(E)$ but it is not fully wild type $(D)$.

\section{ventral cuticle defects in vn mutants}

The spi-group mutants spi, rho, $S$ and pnt are embryonic lethal and have similar cuticle phenotypes; they are shorter than wild type and have deletions of ventral cuticle (Mayer and Nüsslein-Volhard 1988; Fig. 5C). We examined the cuticle phenotype of vn null mutant em. bryos (Table 1; Fig. 5B). vn ${ }^{d d d R Y}$ embryos were shorter $(91 \%, P<.05)$ and the Keilin's organs and ventral black dots were closer together than wild-type $92 \%, P<.05$, $95 \%, P<0.05$, respectively). The measurements show it is ventral cuticle between the Keilin's organs that is deleted in $v n^{d d d R Y}$ embryos. Cuticle measurements show the deletions occur in a similar region in spi-group mutants; spi, and rho have a larger portion of ventral cuticle deleted than $v n$ mutants, but pnt embryos have similar deletions (Mayer and Nüsslein-Volhard 1988).

spi-group mutants have abnormal Keilin's organs with deleted or separated hairs (Mayer and Nüsslein-Volhard 1988) and Keilin's organs defects were also observed in $v n$ embryos. In $v n^{d d d R Y}$ embryos, the sensory hairs were surrounded by a pit structure (Fig. $5 \mathrm{~A}, \mathrm{~B}$ ) and in $v n^{\gamma / \gamma^{3}}$ embryos $50 \%$ of Keilin's organs were missing (data not shown). The head region is affected in spi-group mutants (Mayer and Nüsslein-Volhard 1988) but is apparently normal in $v n$ mutants as judged by the structure of the head skeleton and the inventory of sense organs (data not shown;.

Unlike the spi-group genes, vn is not critical for embryonic survival and null mutants can develop to the pupal stage. Null $v n$ animals have a pleiotropic lethal phase. Most $v n^{\gamma / / \gamma 3}$ individuals die as embryos or as larvae, but a small number pupariate $(\sim 5 \%)$. Individuals that survived to pupariate secreted a pupal case with pattern abnormalities; the pupal cases were shorter and slimmer than wild-type (Fig. 6E,F).

\section{vn and spi interact genetically}

$v n$ and $s p i$ show a strong synergistic genetic interaction suggesting a molecular interdependence. Reducing $v n$ dose in a spi null genotype dramatically worsened the phenotype to produce a collapsed embryo with an extruded head skeleton (Fig. 5C,D). spi; vn double mutants were much more severely affected than the predicted additive phenotype of the single mutants as they lacked almost all ventral denticles and head skeleton structures (Fig. 5E). However, the double mutants were not as severely affected as a $D E R$ null (Fig. 5F). Similar vn-spi genetic interactions were seen in combinations with the strong EMS-induced $v n^{d d d L 6}$ and $s p i^{I I A 14}$ alleles /data not shown), thus, these interactions are not allele specific.

\section{vn interacts with DER and rolled/MAPK}

Genetic interactions are also observable between $v n$ and $D E R$, and vn and rolled/MAPK $(r I)$, a downstream component in the DER pathway (Biggs et al. 1994; Brunner et al. 1994b; O'Neill et al. 1994). Lowering vn dose increased the frequency of missing pattern elements in loss-of-function $D E R$ mutants (Table 2). The gain-offunction alleles, $D E R^{\text {Ellipse }}\left(D E R^{E l p}\right.$; Baker and Rubin $1989)$ and $r 1^{\text {Sevenmaker }}\left(r{ }^{\text {Sem }}\right.$; Brunner et al. 1994b) rescued the viability of $v n$ temperature-sensitive mutants (Table 2). These alleles also rescued proliferation defects in strong and null vn mutants (Fig. 6). vn mutants $\left(v n^{\gamma / / \gamma^{3}}, n=20\right.$ wing discs) have tiny wing discs (Fig. $6 \mathrm{~B}$ ). $v n^{{ }^{d} d d L 6 / \gamma 3}$ discs have a similar phenotype (Fig. $2 \mathrm{~B}_{;} n$ $=44$ wing discs). The $v n$ small wing disc phenotype is rescued by $\mathrm{rl}^{\mathrm{Sem}}$ in most $\mathrm{vn}^{-}$individuals $\left(\mathrm{rl}^{\mathrm{Sem} /+}\right.$; $v n^{d d d L 6 / \gamma 3}, n=68$ wing discs) such that $10 \%$ of discs have the phenotype shown (Fig. $6 \mathrm{C}$ ), and $70 \%$ show a lesser rescue, growing to about twice the size of a null disc (not shown). The $v n$ small wing disc phenotype was rescued dramatically by $D E R^{E l p}\left(D E R^{E l p 1 /+} ; v n^{\gamma 4 / \gamma^{3}}, n\right.$ $=31$ wing discs) such that $70 \%$ of these discs had a duplicated wing pouch (Fig. 6D), and $30 \%$ had a fan shaped wing pouch (not shown). These rescued wing discs were not fully wild-type but resembled those seen in hypomorphic vn mutants, suggesting the hyperactive receptor cannot fully compensate for vn loss (Simcox et al. 1996). The pupal cases secreted by vn mutants (Fig. $6 \mathrm{~F}, v n^{\gamma 4 / \gamma 3}, n=14$ pupae) are shorter and narrower than 
A

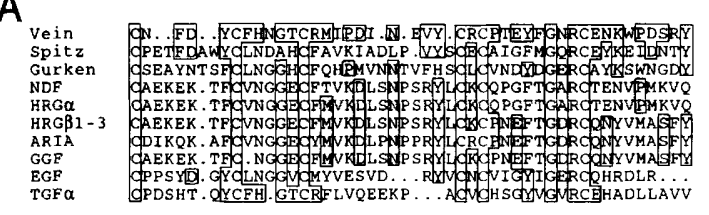

$B$

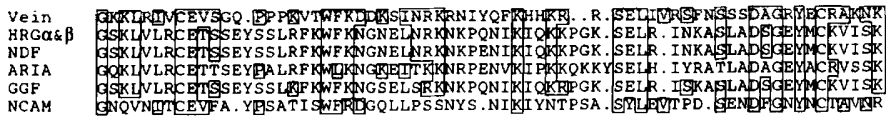

Figure 3. Alignment of the EGF and Ig domains of Vn with similar domains in EGF-like ligands. Comparisons are made relative to Vn with identical amino acids boxed. (A) The EGF-like domain in $\mathrm{Vn}$ has the six invariant cysteines and highly conserved glycine and arginine residues characteristic of the motif. $(B)$ Alignment of the Ig-like domain of $\mathrm{Vn}$. Vn, the neuregulins, and NCAM have a C2 type Ig-like domain that spans about 50-70 residues and is flanked by two invariant cysteine residues. Proteins listed are: the neuregulins [rat NDF, human heregulins $\alpha$ and $\beta 1-3$, chicken ARIA and bovine GGF (Holmes et al. 1992; Wen et al. 1992; Falls et al. 1993; Marchionni et al. 1993; Yardin and Wen 1994)]; EGF/TGF- $\alpha$ proteins [Drosophila Spi (Rutledge et al. 1992) and Grk (NeumanSilberberg and Schüpbach 1993), rat EGF (Simpson et al. 1985), and TGF $($ Marquardt et al. 1984)], and mouse NCAM (Barthels et al. 1987).

wild-type (Fig. 6E). The size of the pupal case in $v n$ animals was rescued toward wild-type by $D E R^{E l p}$ (Fig. 6G, $D E R^{E l p 1 /+} ; v n^{\gamma / / \gamma 3}, n=22$ pupael but not by $r{ }^{\text {Sem }}$, although we did observe a change in the spacing of terminal pattern elements toward wild-type in $r 1^{\mathrm{Sem} /+} ; \mathrm{vn}^{-1-}$ larvae (not shown). Similar suppressed phenotypes were seen with the $v n^{d d d L 6}$ and the hypermorphic $D E R^{E l p B 1}$ alleles (data not shown), therefore, the observed interactions are not allele specific.

\section{vn expression in embryos}

Consistent with a tissue-specific function, $v n$ transcripts are spatially localized (Fig. 7). vn is expressed in blastoderm embryos in two ventrolateral stripes that are brought to the midline as gastrulation proceeds (Fig. 7A). These cells include precursors of the ventrolateral epidermis that is affected in vn and spi; vn mutants (Fig. 5). Expression in midline cells persists but is progressively limited to single cells (Fig. $7 \mathrm{~B}, \mathrm{E}, \mathrm{F})$. In the germ-band retraction stage, cells in the CNS and epidermis express vn (Fig. 7G, insert). The significance of the CNS expression in $v n$ mutants has not been examined. $v n$ is expressed in the anlagen of the amnioserosa at late blastoderm and in the amnioserosa proper until the end of germ-band ex-

12

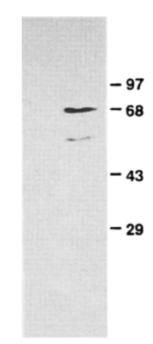

Figure 4. vn encodes a secreted protein. A Schneider's S2 cell line expressing a vn cDNA under the control of the metallothionein promoter was established. $\mathrm{A} \sim 70-\mathrm{kD}$ band that is immunoreactive with anti-Vn antibodies is detected in media from S2-Vn cells (lane 2) but not from untransfected control cells (lane 1). The lower band in lane 2 is a presumed breakdown product. tension (Fig. 7B,C). Survival of the amnioserosa cells is dependent on DER (Clifford and Schüpbach 1992). In late germ-band extended embryos, there is expression in some PNS precursors (Fig. 7D) that, from their position at the end of germ-band retraction, include precursors of the Keilin's organs and a subset of the cells of the chordotonal organs (Fig. 7F,G). The Keilin's organs are often missing or abnormal in $v n^{-}$embryos (Fig. 5B), however, the chordotonal organs appear normal (data not shown). $v n$ is expressed in the head throughout development; in the clypeolabrum, the maxillary and labial lobes, and around the stomodeum (Fig. 7F,G). There are no overt head defects in $v n^{-}$embryos, but the head is severely disrupted in spi;vn mutants (Fig. 5D,E), and DER is re-
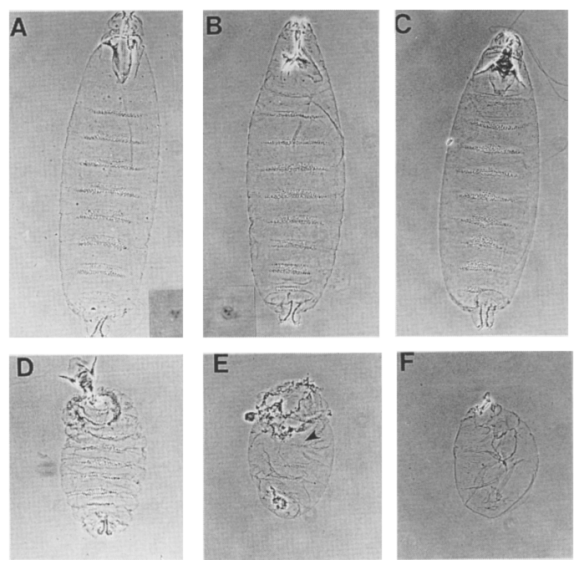

Figure 5. vn mutants have ventrolateral defects and interact genetically with spi. Cuticle preparations of $(A)$ wild-type, $(B)$ $v n^{\text {dddRY/dddRY }},(C)$ spi OD12/VA17,$(D)$ spi $^{\text {OD12/VA17 }} ;$ vn $^{\text {dddRY/ }+},(E)$ spi $i^{O D 12 / V A 17} ; v n^{d d d R Y / d d d R Y}$, and $(F) D E R^{3 F 18 / 3 F 18}$ embryos. The width of the denticle belt and distance between the Keilin's organs is reduced in $v n(B)$ and spi embryos $(C)$ (Table 1). spi embryos with reduced $v n$ dose have an anterior-ventral cuticle hole that extends to the first abdominal segment, an extruded head skeleton and a collapsed body structure $(D)$. spi; vn double mutants have between four and six ventral denticle belts comprised of a small number of denticles each (arrowhead), a large anterior-ventral cuticle hole and a severely reduced head skeleton $|E\rangle$. DER null embryos are more extreme than the $s p i ; v n$ double mutants and lack all denticles $(F)$. 
T'able 1. vn mutants have ventrolateral deletions

\begin{tabular}{lrrr}
\hline & \multicolumn{1}{c}{ Wild-type } & \multicolumn{1}{c}{$v n^{\text {dddRY }}$} & \multicolumn{1}{c}{ WT } \\
\hline I ength of embryo & $13.0 \pm 0.05(n=29)$ & $11.9 \pm 0.28(n=26)$ & 91 \\
I)istance between Keilin's organs & $4.8 \pm 0.05(n=29)$ & $4.4 \pm 0.04(n=27)$ & 92 \\
I)istance between ventral black dots & $8.0 \pm 0.05(n=29)$ & $7.6 \pm 0.08(n=25)$ & 95 \\
\hline
\end{tabular}

I imensions were measured with a micrometer eye piece and are given in arbitrary units \pm S.E. Embryo length was measured at $4 \times$ lower magnification. Distances between sense organs were measured in T3. By Student's $t$-test, these differences are statistically significant $\{P<0.05\}$.

quired for the survival of cells in the head /Clifford and Schüpbach 1992; Raz and Shilo 1992). In late embryos, in expression decays in all ectodermal cells and appears i. the segmental muscles and the gut wall (Fig. $7 \mathrm{H}$ ).

\section{I)iscussion}

\section{vn acts in the DER signaling pathway}

$v n$ shows genetic interactions with components of the IDER signaling pathway (Table 2; Figs. 5 and 6). The most dramatic and informative of these is the rescue of $v n$ null rhenotypes by gain-of-function $D E R$ alleles. vn null ving discs are tiny, arresting growth at the equivalent of a late second/early third-instar-size disc (Simcox et al. 1996), however, vn null wing discs that are heterozygous for the $D E R^{E l p}$ allele are rescued and grow to a large size ( $\because$ ig. 6A,B,D). These discs are not fully wild-type as they have a duplicated wing pouch, which is a phenotype characteristic of $v n$ hypomorphs (Simcox et al. 1996). Thus, the hyperactive DER receptor encoded by the I) $E R^{E l p}$ allele can override the wing proliferation defects

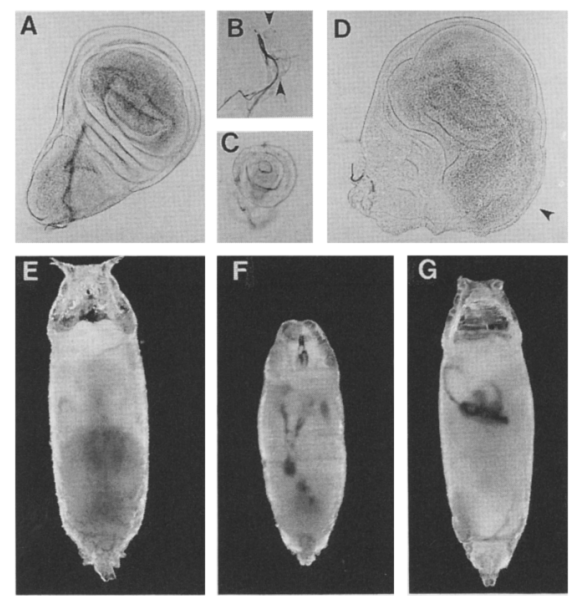

Figure 6. vn interacts genetically with $D E R$ and $r l .(A)$ Wild$t / p e$ wing disc. $(B)$ Tiny wing disc from $v n^{\gamma / / \gamma^{3}}$ larva (arrowheads demarcate disc). (C) Rescued wing disc in $r^{\text {Sem / + }}$; $v n^{d d d L 6 / \gamma^{3}}$ larva. $(D)$ Rescued wing disc in $D E R^{E l p /+} ; v n^{d d d L 6 / \gamma^{3}}$ lirva. The disc has a duplicated wing pouch (arrowhead) and resembles a vn hypomorphic phenotype (Simcox et al. 1996). (E) Vild type pupal case. $(F)$ Shorter and slimmer $v n^{\gamma / / \gamma 3}$ pupal case. (G) Rescued $D E R^{E l p 1 /+} ; V n^{\gamma / / \gamma 3}$ pupal case. The pupal case is close to wild-type size and shape. and partially compensate for vn loss. The $D E R^{E l p}$ allele also rescued the larval patterning defects of $v n$ nulls as reflected in the phenotype of the pupal case (Fig. 6G). These results have two major implications. First, the results show DER is epistatic to $v n$, which is consistent with Vn acting as a ligand for DER. Second, the results suggest that there is redundancy in the signaling system, whereby activation of a hyperactive receptor by another ligand(s) compensates for Vn loss. It is also possible the

Table 2. Genetic interaction between vn and DER and vn and $\mathrm{rl}$

A. Reducing vn dose enhances DER loss-of-function phenotypes

\begin{tabular}{|c|c|c|c|}
\hline \multirow[b]{2}{*}{ Genotype $^{a}$} & \multicolumn{2}{|c|}{ Missing wing vein } & \multirow[b]{2}{*}{$n$ Wings } \\
\hline & $a c v^{b}$ & $\mathrm{~L} 4^{\mathrm{c}}$ & \\
\hline$v n^{d d L 6} / T M 1$ & 0.00 & 0.00 & 50 \\
\hline$v n^{d d d R G} / T M 3$ & 0.00 & 0.00 & 50 \\
\hline$D E R^{\text {top } 1 / t o p 1} ;+/ T M 3$ & 0.17 & 0.01 & 90 \\
\hline$D E R^{\text {top } 1 / \text { top } 1} ; v n^{d d d L 6} / T M 3$ & 0.90 & 0.04 & 80 \\
\hline$D E R^{\text {top } 1 / C A 27} ;+/ T M 3$ & 0.50 & 0.00 & 60 \\
\hline$D E R^{\operatorname{top} 1 / C A 27} ; v n^{d d d L 6 /+}$ & 0.94 & 0.10 & 36 \\
\hline$D E R^{t o p 1 / E C 20} ;+/ T M 3$ & 0.70 & 0.00 & 56 \\
\hline$D E R^{\operatorname{top} 1 / E C 20} ; v n^{d d d L 6 /+}$ & 1.00 & 0.33 & 50 \\
\hline$D E R^{\text {top } 1 / \text { top } 1} ;+T M 8$ & 0.29 & ND & 62 \\
\hline$D E R^{\text {top } 1 / \text { top } 1} ; v n^{d d d R G} / T M 8$ & 1.00 & ND & 52 \\
\hline
\end{tabular}

B. DER and $\mathrm{rl}$ gain-of-function alleles rescue vn temperature-sensitive mutants

\begin{tabular}{|c|c|c|}
\hline \multirow[b]{2}{*}{ Genotype $^{a}$} & \multicolumn{2}{|c|}{ Viability $^{\mathrm{d}}$} \\
\hline & $17^{\circ} \mathrm{C}$ & $25^{\circ} \mathrm{C}$ \\
\hline $\begin{array}{l}v n^{t s W B / \gamma 3} \\
D E R^{E l p 1 /+} ; v n^{t s W B / \gamma 3} \\
r l^{S e m /+} ; v n^{t s W B / \gamma 3}\end{array}$ & $\begin{array}{l}0.39 \\
0.66 \\
0.67\end{array}$ & $\begin{array}{l}0.01 \\
0.50 \\
0.49\end{array}$ \\
\hline \multicolumn{3}{|c|}{$\begin{array}{l}{ }^{\mathrm{a}} v n^{d d d L 6} \text { and } v n^{d d d R G} \text { are strong EMS-induced alleles; } v n^{t s W B} \text { is } \\
\text { an EMS-induced heat-sensitive allele (Simcox et al. 1987); and } \\
v n^{\gamma 3} \text { is a deletion allele (Simcox et al. 1996). DER }{ }^{E l p 1} \text { is a gain- } \\
\text { of-function allele (Baker and Rubin 1989). Other DER alleles } \\
\text { used here are described in Clifford and Schüpbach (1989). } r I^{\text {Sem }} \\
\text { is a gain-of-function } r 1 / M A P K \text { allele (Brunner et al. 1994b). } \\
T M 1, T M 3 \text {, and TM8 are balancer chromosomes. } \\
\text { bacv, anterior crossvein. } \\
{ }^{c} L 4 \text {, longitudinal vein four, which was only partially deleted in } \\
\text { the mutants. } \\
\text { dViability is the fraction of flies expected based on the number } \\
\text { of their heterozygous sibs }(n=100-300 \text { ). }\end{array}$} \\
\hline
\end{tabular}




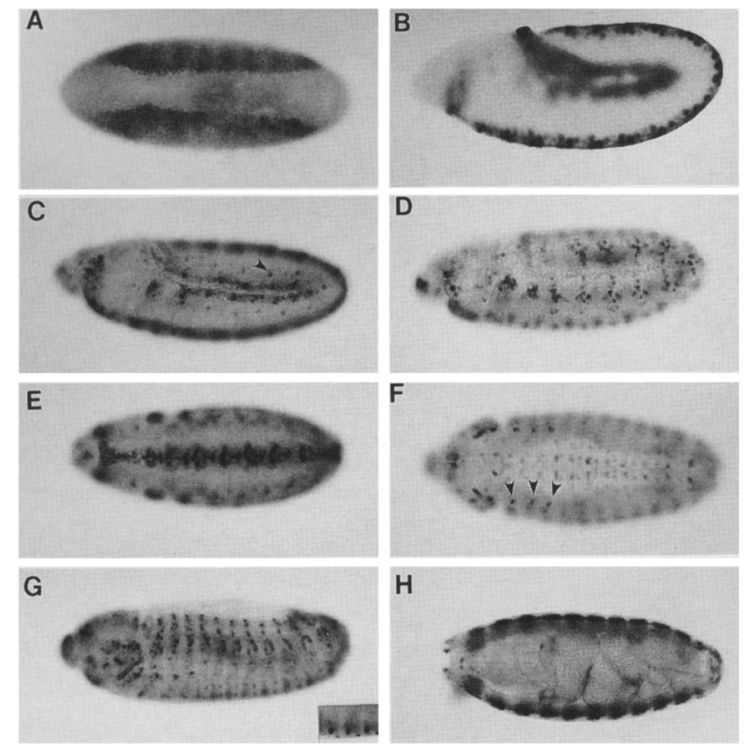

Figure 7. Expression pattern of $v n$ transcripts in embryos. $\langle A|$ Gastrula embryo (stage 5, ventral view). There are two ventrolateral stripes with pair-rule modulation and a central dorsal patch, the presumptive amnioserosa (out of plane of focus), of $v n$ expressing cells. $(B)$ Germ-band extended embryo /stage 10, lateral view). Cells of the ventral midline and the cells of the amnioserosa express vn at high levels. $(C)$ Germ-band extended embryo (stage 10, lateral view). $v n$ is expressed transiently in the presumptive tracheal pits (arrowhead). (D) Germ-band extended embryo (stage 11, lateral view). As epidermal segmentation becomes apparent, expression in the amnioserosa subsides and there is expression in lateral cells that are likely to be a subset of the precursors of the dorsal PNS. There is expression in the head and gnathal segments. $(E)$ Germ-band extended embryo (stage 11 , ventral view). Midline expression is restricted to fewer cells. $(F)$ Germ-band retraction (stage 13, ventral view). There is expression in a small subset of midline cells. (G) Germband retraction (stage 13, lateral view). There is expression in a subset of cells of the PNS dorsal cluster, and cells likely to be precursors of the chordotonal and Keilin's organs. The insert shows CNS cells and epidermal cells at the ventral midline express vn. (H) Late embryo (stage 16). vn is expressed in the mesoderm in the segmental muscles and in the gut wall. Anterior is to the left; in lateral views dorsal is at the top.

hyperactive receptor no longer requires ligand activation; in this scenario some localized cofactor(s) would presumably be required for the spatial restriction of signaling.

vn encodes an EGF-like protein with similarity to the neuregulins

$v n$ encodes secreted proteins with domains characteristic of two protein superfamilies; an EGF-like domain and an Ig-like domain (Figs. 1 and 3). The secreted nature of the proteins is consistent with the non cell-autonomous behavior of $v n$ in clones (Wurst et al. 1984; Simcox et al. 1987; García-Bellido et al. 1994). The EGF domain, found in all EGFR ligands, is important for receptor binding and activation (Groenen et al. 1994). The Ig-like domain, known to be involved in protein-protein interaction (Williams and Barclay 1988), may facilitate Vn dimerization or interaction with other extracellular proteins. The only known ligands that have both EGF-like and Ig-like domains are the vertebrate neuregulins, also known as Neu differentiation factor, the heregulins, ARIA, and glial growth factors (Holmes et al. 1992; Wen et al. 1992; Falls et al. 1993; Marchionni et al. 1993; Yardin and Wen 1994). The neuregulins were described initially as direct ligands for neu but later shown to bind its relatives, erbB3 and erbB4, furthermore, signaling through the neuregulins can occur through receptor heterodimers (Caraway and Cantley 1994). In Drosophila, DER is the only $E G F R$-like gene that has been identified, therefore, it is likely Vn directly binds and activates DER. However, we cannot exclude the possibility that Vn activation of DER signaling is indirect and similar to the situation with the neuregulins that bind specific receptors but can activate others in receptor heterodimers or, indeed, occurs via a parallel pathway. The potential of Vn as a direct DER ligand can be tested by use of the tissue-culture system that was developed to show Spi activates DER (Schweitzer et al. 1995b).

\section{vn is a localized component in the DER signaling pathway}

DER is expressed broadly in embryos, but required in specific cells (Kammermeyer and Wadsworth 1987; Zak et al. 1990); for example, DER is expressed throughout the embryonic epidermis, but only the ventral epidermis is affected in mutants. The EGF-like ligands encoded by $v n$ and spi activate DER signaling, and, thus, spatial restriction of these ligands may confer tissue-specificity to DER function in the developing zygote, analogous to the situation in the ovary where Grk restricts DER activation (Neuman-Silberberg and Schüpbach 1993; González-Reyes et al. 1995; Roth et al. 1995).

At least three mechanisms operate to control the spatial and temporal pattern of Spi/DER signaling. Spi is expressed broadly, and, therefore, its distribution cannot restrict receptor function directly; however, processing Spi into a secreted factor is apparently required for its activity (Rutledge et al. 1992; Schweitzer et al. 1995b). Thus, the first mechanism operates to restrict the spatial production of the active Spi ligand and may depend on the activity of cofactors that are localized. Spi, like most EGF proteins, has a predicted transmembrane domain carboxy-terminal to the EGF-like region that anchors the protein to the cell in a transmembrane pro-form (Rutledge et al. 1992). Proteolytic cleavage is thought to release the soluble form and tissue-culture experiments, and the activity of spi transgenes in embryos suggests it is the soluble form of Spi, secreted Spi (sSpi), that is active (Schweitzer et al. 1995b). Genetic experiments suggest that the localized production of sSpi may require Rho and S function: sSpi can rescue ventral fates in rho and $S$ mutant embryos, suggesting it acts after these genes, consistent with a possible role for Rho and $S$ in 
the processing of Spi into its active form (Schweitzer et al. 1995b). Thus, the generation of sSpi may be limited to cells in the ventrolateral domain that express Rho and S. Two mechanisms operate to limit the duration of Spi/ DER signaling. The first of these involves argos which encodes an EGF-like protein with an unusual EGF domain in which the spacing between the third and fourth cysteines is much greater than in other EGF-like proteins (Freeman et al. 1992). Genetic and biochemical evidence suggests Argos is an inhibitor of the activation of DER by Spi (Schweitzer et al. 1995a). Interestingly, argos expression is up-regulated in cells that have undergone Spi/DER signaling, effecting a negative feedback loop to limit DER activation in neighboring cells (Golembo et al. 1996). In a second mechanism, the production of the receptor itself is affected, as $D E R$ transcripts were shown to be down-regulated in cells that recently have undergone DER signaling (Sturtevant et al. 1994).

The regulation of $\mathrm{Vn} / \mathrm{DER}$ signaling is different from Spi/DER signaling. First, unlike spi, vn is expressed in a localized pattern and, thus, would limit Vn/DER signaling to cells in the Vn expression domain. Second, the Vn proteins we characterized lack a potential membranespanning domain to anchor them to the cell surface and would not require a processing step to release a soluble form. In the embryo, vn and spi are expressed in overlapping domains and our genetic data suggest they function together to achieve the required level of DER activation for normal development of ventrolateral cells. As $\mathrm{Vn} / \mathrm{DER}$ signaling occurs in the same domain as Spi/ DER signaling, it would be modulated by down-regulation of the receptor and may also be effected by Argos inhibition, although this will have to be tested directly. The situation is different in the wing, where $\mathrm{Vn}$ is expressed primarily in developing interveins, and the genes that modulate Spi/DER signaling (rho, $S$, and argos) are expressed in developing veins (Heberlein et al. 1993; Sturtevant et al. 1993; Sawamoto et al. 1994; Sturtevant and Bier 1995; Simcox et al. 1996). Mirroring the situation in the embryo, prevein cells that are presumed to have undergone high levels of DER activation down-regulate expression of the receptor, so that in pupal wings, DER expression colocalizes with vn expression in intervein regions (Sturtevant et al. 1994; Simcox et al. 1996). Thus, the development of intervein cells apparently requires Vn/DER signaling and is not subject to modulation by the factors that influence Spi/DER signaling in the developing veins.

\section{vein and spi interact genetically}

Unlike spi mutants which are embryonic lethal, vn mutants have a pleiotropic lethal phase and can survive to pupate. The ventral cuticle defects in $v n^{-}$embryos are correspondingly milder than those seen in spi ${ }^{-}$embryos (Fig. 5B,C). There are strong genetic interactions between $v n$ and spi, suggesting the two genes function in the same process. Lowering vn dose worsened the spi phenotype and the double mutants were much more severely affected than would be predicted from an additive effect (Fig. 5D,E). Both genes encode EGF-like proteins and interact genetically with $D E R$ and, therefore, are probable ligands for DER. This has been confirmed biochemically for Spi (Schweitzer et al. 1995b).

The spi-vn interaction and suppression of vn phenotypes by $D E R^{E l p}$ alleles reveals an interplay between the ligands that we interpret according to the following model (Fig. 8). In the wild-type situation, both Spi and Vn contribute to activating DER signaling to the threshold level required for normal ventral patterning. Eliminating $v n$ or spi reduces ventral pattern elements and is more extreme in spi mutants. A hyperactive receptor (DER ${ }^{\mathrm{Elp}}$ ) can return signaling to near wild-type levels in a $v n \mathrm{mu}$ tant by augmenting Spi/DER signaling. Reducing the $v n$ dose in a spi mutant further reduces signaling compared with the spi mutant with wild-type levels of vn and removal of both vn and $s p i$ in the double mutant severely affects ventral patterning. However, this phenotype is not as severe as that seen in a DER null mutant; these

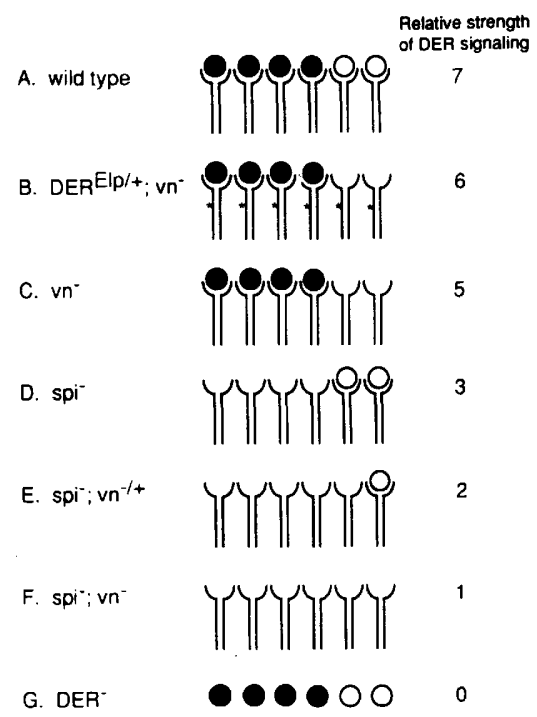

Figure 8. Model of Spi/DER and Vn/DER signaling in the ventrolateral cells in the embryo. $(A)$ Wild-type. Spi and Vn activate DER signaling to the threshold for normal development. The contribution of Spi to the overall level of signaling is greater and represented here as more receptor dimers binding Spi. We show Vn binding DER directly, however, the effect on DER could be indirect via binding in a receptor heterodimer or via a parallel pathway. $(B) D E R^{E l p /+}$; vn. The absence of $\mathrm{Vn}$ is compensated for by an enhancement of Spi/DER signaling by the hyperactive $\mathrm{DER}^{\mathrm{Elp}}$ receptor ( $\left.{ }^{*}\right)$ and the ventral cuticle is almost wild-type. (C) vn. In the absence of Vn, the level of DER activation is decreased and there are subtle ventral defects. $(D)$ spi. In the absence of Spi, DER signaling is substantially reduced and there are ventral defects. $(E) s p i ; v n /+$. Lowering Vn dose in the absence of Spi increases the severity of the ventral defects over those seen in a spi mutant. $(F)$ spi; vn. In the absence of Spi and Vn, DER is active at a very low level and there are severe ventral deletions. The remaining DER signal is most likely due to basal activity of the receptor or activity of another ligand or cofactor. (G) DER. In the absence of DER there is no signaling and the ventral cuticle is completely deleted. (O) $\mathrm{Spi}$ (O) Vn; (T) ) DER; ().) $\mathrm{DER}^{\mathrm{El}}$. 
embryos have no ventral cuticle. There are at least three possibilities that explain this observation. First, maternal $s i^{+}$or $v n^{+}$products may mask the severity of the $s p i$; vn zygotic phenotype, but germ cell and ovary transplants (respectively) suggest spi and $v n$ do not have maternal effects (T. Schüpbach, pers. comm.; A. Simcox and E. Hersperger, unpubl.). More likely, the difference could be caused by basal activity of the receptor or activation by another (unknown) ligand or cofactor.

The vertebrate EGFR family and its ligands are implicated in human cancer, and understanding the extracellular events that lead to receptor activation will be important for the development of therapies targeted at ligand-receptor interaction (Jeschke et al. 1995; Levitzky and Gazit 1995). The intriguing similarity between Vn and the neuregulins and the emerging complexity of EGFR signaling in Drosophila, including the discovery of the inhibitor Argos (Schweitzer et al. 1995a; Golembo et al. 1996), suggests the fly will be an important model for understanding these extracellular events.

\section{Materials and methods}

Drosophila stocks

The $v n$ alleles $v n^{d d d R Y}$ and $v n^{\gamma 4}$ are null as they disrupt the transcribed region (Fig. $1 \mathrm{~A}$ ). $v n^{\gamma 3}$, is a gross deletion, $v n^{d d d R G}$ and $v n^{d d d L 6}$ are strong EMS-induced alleles and $v n^{t s W B}$ is a temperature-sensitive, EMS-induced allele (Simcox et al. 1996). $s p i^{O D 12}$ and $s p i^{V A 17}$ are overlapping deletions and the combination is $s p i^{-}$(Rutledge et al. 1992). The $D E R^{3 F 18}$ allele is a deficiency, $D E R^{\text {top } 1}, D E R^{C A 27}$, and $D E R^{E C 20}$ are described in Clifford and Schüpbach (1989).

\section{Embryo cuticle preparation}

Embryos were manually dechorionated, devitellinized, and cooked in lactic acid and $70 \%$ ethanol $(9: 1)$ at $45^{\circ} \mathrm{C}$ overnight. Cleared embryos were mounted in Hoyer's medium.

\section{Lethal phase determination}

The hatch rate of red $v n^{\gamma 4} / r e d v n^{\gamma 3}$ individuals was determined by counting of total and unhatched eggs from a cross of red $v n^{\gamma 4} /$ TM3 $X$ red $v n^{\gamma 3} /+$. Of 412 eggs, 73 failed to hatch, these should be mainly the red $v n^{\gamma 4} /$ red $v n^{\gamma 3}$ embryos as the three other genotypes are fully viable, thus the embryonic lethality rate for red $v n^{\gamma 4} /$ red $v n^{\gamma 3}$ is $\sim 70 \%$. (We did not check what portion of the unhatched eggs were unfertilized, thus, this number may be slightly over estimated.) Eighty-three hatched red $v n^{\gamma 4} /$ red $v n^{\gamma 3}$ individuals were separated in the second and early third instars and allowed to develop without competition from their more vigorous sibs, 18 of these pupariated, none developed to the pharate or adult stage.

\section{Cloning the vn genomic region}

Cloning of the $v n$ region by transposon tagging was initiated from a $\mathrm{P}$ element at 64F that is associated with the $v n^{D 4}$ allele (kindly provided by R. Karess, Centre National de la Recherche Scientifique, Gif-sur-Yvette, France). This P element is responsible for the $v n$ phenotype because the allele reverted when the $P$ element excised. Sequences flanking the P DNA were used to isolate a set of overlapping clones from a $\lambda$ Charon 4 wild-type
Drosophila genomic library (Maniatus et al. 1978). A total of 52 $\mathrm{kb}$ around the P-element insert was cloned.

\section{Isolation of vn $c D N A s$}

A 214-bp genomic fragment (corresponding to nucleotides 2580-2794; Fig. 1B) was used as the initial probe to isolate three phage from a disc cDNA library (A. Cowman and G. Rubin, University of California, Berkeley). A cDNA fragment derived from these clones (corresponding to nucleotides 3424-3980; Fig. 1B) was then used as a probe to isolate seven more cDNAs [three from an embryo library (T. Kornberg, University of California, San Francisco) and four from the disc library (A. Cowman and G. Rubin)|. All contained a single EcoRI fragment and were subcloned into $\mathrm{pBSKS}^{+}$for sequencing. The combination of two of these cDNAs gives a 6864 -bp sequence that corresponds in size to the larger message $(6.8 \mathrm{~kb})$ seen in Northern analysis. Sequencing of the cDNA clones revealed two forms that differed by the presence or absence of a 1782-bp intron 16 of 8 cDNAs that cover this region have the 1782 -bp sequence). cDNAs that splice out the intron are $5082 \mathrm{bp}$ in length and correspond to the smaller transcript seen in Northern analysis $(5 \mathrm{~kb})$.

\section{DNA sequencing and analysis}

The $v n$ cDNA clones and some genomic clones were sequenced on both strands by use of a USB Sequenase 2.0 kit with singlestranded templates. Gene-specific primers were designed to extend the sequence on a given strand. Initial searches of the data base for similarities were performed with BLAST at NCBI. Sequence alignments were done with the Genetics Computer Group Wisconsin Package with the PileUp program.

\section{Generation of Vn antibody}

Anti-Vn antibodies were generated by cloning a partial vn cDNA (nucleotides 1282-2705, Fig. 1B) into the EcoRI site of the pRSET expression vector (Invitrogen). Polyclonal rabbit antibodies were generated against the resulting purified fusion protein (Cocalico Biologicals, Inc.).

\section{Activation of UAS-vn}

The complete open reading frame of a vn cDNA (1679-3980, Fig. 1B) was cloned into the $\mathrm{XbaI} / \mathrm{Xhol}$ site in pUAST (Brand and Perrimon 1993) and introduced into flies by germ-line transformation. The UAS-vn gene and the T80-GAL4 driver were crossed into a $v n$ mutant background $\left(v n^{\text {dddL6/r3 }}\right)$. The $v n$ mutants (UAS-vn/T80-gal 4; vn ${ }^{d d d L 6 / \gamma 3}$ and UAS-vn/CyO; $v n^{d d d L 6 / \gamma 3}$ ) were recognized by the red Malphigian tubule marker and examined for their larval and wing disc phenotypes. Approximately $50 \%$ of these larvae showed a partially rescued phenotype when compared with $v n^{d d d L \sigma / \gamma^{3}}$ controls; they were bigger, more vigorous and had large wing discs. The $v n^{d d d L / \gamma 3}$ wing disc phenotype is $100 \%$ penetrant (Simcox et al. 1996), and, thus, we assume these rescued animals were UAS-Vn/T80gal $4 ; v^{d d d L 6 / \gamma 3}$.

\section{Tissue culture}

Schneider's S2 cells were grown in Drosophila Schneider medium (GIBCO), supplemented with $10 \%$ fetal bovine serum. Ten micrograms of a Vn-expression construct, which contained nucleotides 1679-3980 inserted into pMK33, was used for transfection with Lipofectin (GIBCO) in serum-free medium following the manufacturer's protocol. A stable cell line was estab- 
lished following selection in $200 \mu \mathrm{g} / \mathrm{ml}$ hygromycin B /Calbiochem). S2-Vn cells were induced for $36 \mathrm{hr}$ in serum-free medium containing $0.7 \mathrm{mM} \mathrm{CuSO}_{4}$.

\section{Acknowledgments}

We thank A. Shearn in whose lab this work was initiated, R. Karess, T. Schüpbach, N. Perrimon, D. Brunner, E. Hafen, N. Baker, and the stock centers for stocks, M. Phillips for some sequencing, R. Flannagan for help with Northern analysis, $H$. Vaessin for looking at the embryonic expression, C. Beall, E. Gottlieb, A. Shearn and H. Vaessin for comments on the manuscript, T. Schüpbach for sharing unpublished results, and N. Tripoulas for suggesting a possible link to the DER pathway. This work was supported by grants from the American Cancer Society (33602-55-00) and the National Science Foundation (IBN-9253112 and IBN-9421740) to A.S. The sequence data in this paper have been submitted to the GenBank data library under accession no. U67935.

The publication costs of this article were defrayed in part by payment of page charges. This article must therefore be hereby marked "advertisement" in accordance with 18 USC section 1734 solely to indicate this fact.

\section{References}

Aroian, R.V., M. Koga, J.E. Mendel, Y. Ohshima, and P.W. Sternberg. 1990. The let-23 gene necessary for Caenorhabditis elegans vulval induction encodes a tyrosine kinase of the EGF receptor subfamily. Nature 348: 693-699.

Baker, N.E. and G.M. Rubin. 1989. Effect on eye development of dominant mutations in Drosophila homologue of the EGF receptor. Nature 340: 150-153.

Barthels, D., M.J. Santoni, W. Wille, C. Ruppert, J.C. Chaix, M.R. Hirsch, J.C. Fontecilla-Camps, and C. Goridis. 1987. Isolation and nucleotide sequence of mouse NCAM cDNA that codes for a $\mathrm{Mr} 79,000$ polypeptide without a membranespanning region. EMBO J. 6: 907-914.

Baumann, P. and H. Skaer. 1993. The Drosophila EGF receptor homologue (DER) is required for Malpighian tubule development. Development S 1993: 65-75.

Bier, E., L.Y. Jan, and Y.-N. Jan. 1990. rhomboid, a gene required for dorsoventral axis establishment and peripheral nervous system development in Drosophila melanogaster. Genes \& Dev. 4: 190-203.

Biggs, W.H., K.H. Zavitz, B. Dickson, A. van der Straten, D. Brunner, E. Hafen, and L. Zipursky. 1994. The Drosophila rolled locus encodes a MAP kinase required in the sevenless signal transduction pathway. EMBO I. 13: 1628-1635.

Brand, A. and N. Perrimon. 1993. Targeted gene expression as a means of altering cell fates and generating dominant phenotypes. Development 118: 401-415.

Briggs, M.S. and L.M. Gierasch. 1986. Molecular mechanisms of protein secretion: The role of the signal sequence. Adv. Prot. Chem. 38: 109-180.

Brunner, D., K. Ducker, N. Oellers, E. Hafen, H. Scholz, and C. Klämbt. 1994a. The ETS domain protein Pointed-P2 is a target of MAP kinase in the Sevenless signal transduction pathway. Nature 370: 386-389.

Brunner, D., N. Oellers, J. Szabad, W.H. Biggs, S.L. Zipursky, and E. Hafen. 1994b. A gain-of-function mutation in Drosophila MAP kinase activates multiple receptor tyrosine kinase signaling pathways. Cell 76: 875-888.

Caraway, K.L. and L.C. Cantley. 1994. A neu aquaintance for erbB3 and erbB4: A role for receptor heterodimerization in growth signaling. Cell 78: 5-8.

Cavener, D.R. 1987. Comparison of consensus flanking translational start sites in Drosophila and vertebrates. Nucleic Acids Res. 15: 1353-1361.

Clifford, R.T. and T. Schüpbach. 1989. Coordinately and differentially mutable activities of torpedo, the Drosophila melanogaster homolog of the vertebrate EGF receptor gene. $\mathrm{Ge}$ netics 122: 771-787.

- 1992. The torpedo (DER) receptor tyrosine kinase is required at multiple times during Drosophila embryogenesis. Development 115: 853-872.

- 1994. Molecular analysis of the Drosophila EGF receptor homolog reveals that several genetically defined classes of alleles cluster in subdomains of the receptor protein. $\mathrm{Ge}$ netics 137: 531-550.

Díaz-Benjumea, F.J. and A. García-Bellido. 1990. Genetic analysis of the wing vein pattern of Drosophila. Roux's Arch. Dev. Biol. 198: 336-354.

Egan, S.E. and R.A. Weinberg. 1993. The pathway to signal achievement. Nature 365: 781-783.

Falls, D., K.M. Rosen, G. Corfas, W.S. Lane, and G. Fischbach. 1993. ARIA, a protein that stimulates acetylcholine receptor synthesis, is a member of the neu ligand family. Cell 72: $801-815$.

Freeman, M., C. Klämbt, C.S. Goodman, and G.M. Rubin. 1992. The argos gene encodes a diffusible factor that regulates cell fate in the Drosophila eye. Cell 69: 963-975.

García-Bellido, A., F. Cortes, and M. Milan. 1994. Cell interactions in the control of size in Drosophila wings. Proc. Natl. Acad. Sci. 91: 10222-10226.

Gassmann, M., F. Casagranda, D. Orioli, H. Simon, C. Lai, R. Klein, and G. Lemke. 1995. Aberrant neural and cardiac development in mice lacking the ErbB4 neuregulin receptor. Nature 378: 390-394.

Golembo, M., R. Schweitzer, M. Freeman, and B.-Z. Shilo. 1996. argos transcription is induced by the Drosophila EGF receptor pathway to form an inhibitory feedback loop. Development 122: 223-230.

González-Reyes, A., H. Elliott, and D. St Johnston. 1995. Polarization of both major body axes in Drosophila by gurkentorpedo signaling. Nature 375: 654-658.

Groenen, L.C., E.C. Nice, and A.W. Burgess. 1994. Structurefunction relationaships for the EGF/TGF- $\alpha$ family of mitogens. Growth Factors 11: 235-257.

Heberlein, U., I.K. Hariharan, and G.M. Rubin. 1993. Star is required for neuronal differentiation in the Drosophila retina and displays dosage-sensitive interactions with Rasl. Dev. Biol. 160: 51-63.

Hill, R.J. and P.W. Sternberg. 1992. The gene lin-3 encodes an inductive signal for vulval development in C. elegans. $\mathrm{Na}$ ture 358: 470-476.

Holmes, W.E., M.X. Sliwokowski, R.W. Akita, W.J. Henzel, J. Lee, J.W. Park, D. Yansura, N. Abadi, H. Raab, G.D. Lewis, H.M. Shepard, W.-J. Kuang, W.I. Wood, D.V. Goeddel, and R.L. Vandlen. 1992. Identification of heregulin, a specific activator of p185erbB2. Science 256: 1205-1210.

Jeschke, M., W. Wels, W. Dengler, R. Imber, E. Stocklin, and B. Groner. 1995. Targeted inhibition of tumor-cell growth by recombinant heregulin-toxin fusion proteins. Int. I. Cancer 60: $730-739$.

Kammermeyer, K.L. and S.C. Wadsworth. 1987. Expression of Drosophila epidermal growth factor receptor homologue in mitotic cell populations. Development 100: 201-210.

Katzen, A.L., T. Kornberg, and J.M. Bishop. 1991. Expression during Drosophila development of DER, a gene related to erbB-l and neu: Correlations with mutant phenotypes. Dev. 
Biol. 145: 287-301.

Kim, S.H., and S.T. Crews. 1993. Influence of Drosophila ventral epidermal development by the CNS midline cells and spitz class genes. Development 118: 893-901.

Klämbt, C. 1993. The Drosophila gene pointed encodes two ETS-like proteins which are involved with the development of the midline glial cells. Development 117: 163-176.

Kolodkin, A., A. Pickup, D. Lin, C.S. Goodman, and U. Banerjee. 1994. Characterization of Star and its interactions with sevenless and EGF receptor during photoreceptor development in Drosophila. Development 120: 1731-1745.

Kuo, Y.M., N. Jones, B. Zhou, S. Panzer, V. Larson, and S.K. Beckendorf. 1996. Salivary duct determination in Drosophila: Roles of the EGF receptor signaling pathway and the transcription factors Fork head and Trachealess. Development 122: 1909-1917.

Lee, K.-F., H. Simon, H. Chen, B. Bates, M.-C. Hung, and C. Hauser. 1995. Requirement for neuregulin receptor erbB2 in neural and cardiac development. Nature 378: 394-398.

Levitzky, A. and A. Gazit. 1995. Tyrosine-kinase inhibition. Science 267: 1782-1788.

Maniatis, T., R.C. Hardison, E. Lacy, J. Lauer, C. O'Connell, D. Ouon, D.K. Sim, and A. Efstratiadis. 1978. The isolation of structural genes from libraries of eucaryotic DNA. Cell 15: 687-697.

Marchionni, M., A. Goodearl, M. Chen, O. Bermingham-McDonogh, C. Kirk, M. Hendricks, F. Danehy, D. Misumi, J. Sudalter, K. Kobayashi, D. Wroblewski, C. Lynch, M. Baldassare, I. Hiles, J. Davis, J. Hsuan, N. Totty, M. Otsu, R. McBurney, M. Waterfield, P. Stroobant, and D. Gwynne. 1993. Glial growth factors are alternately spliced erbB2 ligands expressed in the nervous system. Nature 362: 312362.

Marquardt, H., M. Hunkapiller, L. Hood, and G. Todaro. 1984. Rat transforming growth factor type 1: Structure and relation to epidermal growth factor. Science 223: 1079-1082.

Mayer, U. and C. Nusslein-Volhard. 1988. A group of genes required for pattern formation in the ventral ectoderm of the Drosophila embryo. Genes \& Dev. 2: 1496-1511.

Meyer, D. and C. Birchmeier. 1995. Multiple essential functions of neuregulin in development. Nature 378: 386-390.

Miettinen, P.J., J.E. Berger, J. Meneses, Y. Phung, R.A. Pedersen, Z. Werb, and R. Derynck. 1995. Epithelial immaturity and multiorgan failure in mice lacking epidermal growth factor receptor. Nature 376: 337-341.

Mount, S.M., C. Burks, G. Hertz, G.D. Stormo, O. White, and C. Fields. 1992. Splicing signals in Drosophila: Intron size, information content, and consensus sequence. Nucleic Acids Res. 20: 4255-4262.

Neuman-Silberberg, F. and T. Schüpbach. 1993. The Drosophila gene gurken produces a dorsally localized RNA and encodes a TGFa-like protein. Cell 75: 165-174.

O'Neill, E.M., I. Rebay, R. Tijan, and G.M. Rubin. 1994. The activities of two Ets-related transcription factors required for Drosophila eye development are modulated by the Ras/ MAPK pathway. Cell 78: 137-147.

Puro, J. 1982. New mutants. Dros. Inf. Serv. 58: 205-208.

Raz, E. and B.-Z. Shilo. 1992. Dissection of the faint little ball (flb) phenotype: Determination of the development of the Drosophila central nervous system by early interactions in the ectoderm. Development 114: 113-123.

- 1993. Establishment of ventral cell fates in the Drosophila embryonic ectoderm requires DER, the EGF receptor homolog. Genes \& Dev. 7: 1937-1948.

Rogers, S., R. Wells, and M. Rechsteiner. 1986. Amino acid sequences common to rapidly degraded proteins: The PEST hypothesis. Science 234: 364-368.

Roth, S., S. Neuman-Silberberg, G. Barcelo, and T. Schüpbach. 1995. cornichon and the EGF receptor signaling process are necessary for both anterior-posterior and dorsal-ventral pattern formation in Drosophila. Cell 81: 967-978.

Rutledge, B.J., K. Zhang, E. Bier, Y.N. Jan, and N. Perrimon. 1992. The Drosophila spitz gene encodes a putative EGF-like growth factor involved in dorsal-ventral axis formation and neurogenesis. Genes \& Dev. 6: 1503-1517.

Sawamoto, K., H. Okano, Y. Kobayakawa, S. Hayashi, K. Mikoshiba, and T. Tanimura. 1994. The function of argos in regulating cell fate decisions during Drosophila eye and wing vein development. Dev. Biol. 164: 267-276.

Schejter, E.D., D. Segal, L. Gazer, and B.-Z. Shilo. 1986. Alternative 5 ' exons and tissue-specific expression of the Drosophila EGF receptor homolog transcripts. Cell 46: 1091-1101.

Schweitzer, R., R. Howes, R. Smith, B.-Z. Shilo, and M. Freeman. 1995a. Inhibition of Drosophila EGF receptor activation by the secreted protein Argos. Nature 376: 699-702.

Schweitzer, R., M. Shaharabany, R. Seger, and B.-Z. Shilo. 1995b. Secreted spitz triggers the DER signaling pathway and is a limiting component in embryonic ventral ectoderm determination. Genes \& Dev. 9: 1518-1529.

Shearn, A., T. Rice, A. Garen, and W. Gehring. 1971. Imaginal abnormalities in lethal mutants of Drosophila. Proc. Natl. Acad. Sci. 68: 2294-2598.

Shilo, B.Z. and E. Raz. 1991. Developmental control by the Drosophila EGF receptor homolog DER. Trends Genet. 7: 388-392

Sibilia, M. and E.F. Wagner. 1995. Strain-dependent epithelial defects in mice lacking the EGF receptor. Science 269: 234 238 .

Simcox, A.A., G. Wurst, E. Hersperger, and A. Shearn. 1987. The defective dorsal discs gene of Drosophila is required for the growth of specific imaginal discs. Dev. Biol. 122: 559-567.

Simcox, A., G. Grumbling, B. Schnepp, C. Bennington-Mathias, E. Hersperger, and A. Shearn. 1996. Molecular, phenotypic, and expression analysis of vein, a gene required for growth of the Drosophila wing disc. Dev. Biol. 177: 475-489.

Simpson, R., J. Smith, R. Moritz, M. O'Hare, P. Rudland, J. Morrison, C. Lloyd, B. Grego, A. Burgess, and E. Nice. 1985. Rat epidermal growth factor: Complete amino acid sequence. European J. Biochemistry 153: 629-637.

Sturtevant, M.A. and E. Bier. 1995. Analysis of the genetic hierarchy guiding wing vein development in Drosophila. Development 121: 785-801.

Sturtevant, M.A., M. Roark, and E. Bier. 1993. The Drosophila rhomboid gene mediates the localized formation of wing veins and interacts genetically with components of the EGF-R signaling pathway. Genes \& Dev. 7: 961-973.

Sturtevant, M.A., J.W. O'Neill, and E. Bier. 1994. Down-regulation of Drosophila Egf-r mRNA levels following hyperactivated receptor signaling. Development 120: 2593-2600.

Threadgill, D.W., A.A. Dlugosz, L.A. Hansen, T. Tennenbaum, U. Lichti, D. Yee, C. LaMantia, T. Mourton, K. Herrup, R.C. Harris, et al. 1995. Targeted disruption of mouse EGF receptor: Effect of genetic background on mutant phenotype. Science 269: 230-234.

von Heijne, G. 1986. A new method for predicting signal sequence cleavage sites. Nucleic Acids Res. 14: 4683-4690.

- 1987. Sequence analysis in molecular biology. Academic Press, San Diego CA.

Wen, D., E. Peles, R. Cupples, S.V. Suggs, S.S. Bacus, Y. Luo, G. Trail, S. Hu, S.M. Silbiger, R.B. Levy, R.A. Koski, H.S. Lu, and Y. Yarden. 1992. Neu differention factor: A transmembrane glycoprotein containing an EGF domain and an immu- 
noglobulin homology unit. Cell 69: 559-572.

Wharton, K.A., B. Yedvobnick, V.G. Finnerty, and S. ArtavanisTsakonas. 1985. opa: A novel family of transcribed repeats shared by the Notch locus and other developmentally regulated loci in D. melanogaster. Cell 40: 55-62.

Wilder, E.L. and N. Perrimon. 1995. Dual functions of wingless in the Drosophila leg imaginal disc. Development 121: 477488.

Williams, A.F. and A.N. Barclay. 1988. The immunoglobulin superfamily-domains for cell surface recognition. Annu. Rev. Immunol. 6: 381-405.

Wurst, G., E. Hersperger, and A. Shearn. 1984. Genetic analysis of transdetermination in Drosophila. II. Transdetermination to wing of leg discs from a mutant which lacks wing discs. Dev. Biol. 106: 147-155.

$\mathrm{Xu}, \mathrm{T}$. and G.M. Rubin. 1993. Analysis of genetic mosaics in developing and adult Drosophila tissues. Development 117: 1223-1237.

Yardin, Y. and D. Wen. 1994. Neu differentiation factor (NDF) and the neuregulin family. In Guidebook to cytokines and their receptors (ed. N.A. Nicola), pp. 146-149. Oxford University Press, Oxford, UK.

Zak, N.B., R.J. Wides, E.D. Schejter, E. Raz, and B.Z. Shilo. 1990. Localization of the DER/flb protein in embryos: Implications on the faint little ball lethal phenotype. Development 109: 865-874. 


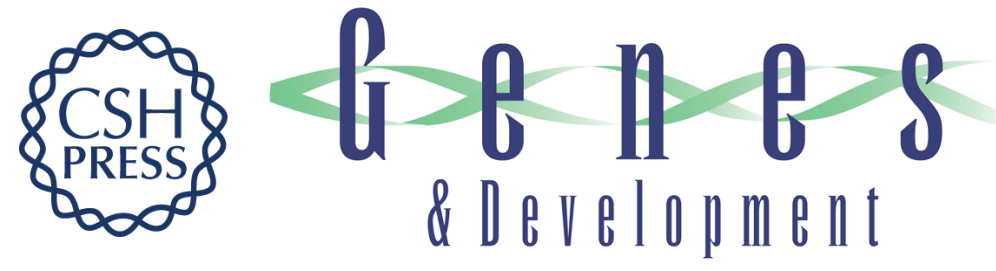

\section{Vein is a novel component in the Drosophila epidermal growth factor receptor pathway with similarity to the neuregulins.}

B Schnepp, G Grumbling, T Donaldson, et al.

Genes Dev. 1996, 10:

Access the most recent version at doi:10.1101/gad.10.18.2302

References This article cites 73 articles, 28 of which can be accessed free at:

http://genesdev.cshlp.org/content/10/18/2302.full.html\#ref-list-1

License

Email Alerting

Service

Receive free email alerts when new articles cite this article - sign up in the box at the top right corner of the article or click here.

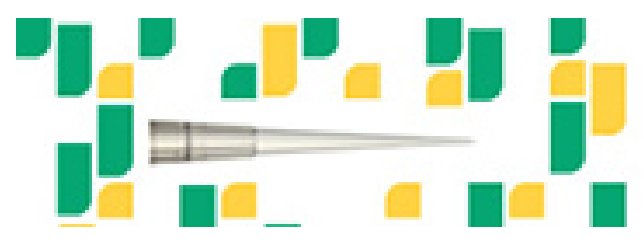

Focused on your science. 